\title{
Prominent Intraductal Component Present
}

National Cancer Institute

\section{Source}

National Cancer Institute. Prominent Intraductal Component Present. NCI Thesaurus. Code C54687.

A morphologic finding that indicates the presence of a substantial neoplastic cellular proliferation within a ductal structure. 